Decision Inertia in Critical Incidents

\author{
Nicola Power ${ }^{*}$ \\ Department of Psychology, Lancaster University, UK
}

Laurence Alison

Psychological Sciences, University of Liverpool, UK

*Correspondence concerning this article should be addressed to Dr Nicola Power, Department of Psychology, Lancaster University, LA1 4YF, United Kingdom (e-mail: n.power3@lancaster.ac.uk). 


\begin{abstract}
When presented with competing options, critical incident decision makers often struggle to commit to a choice (in particular when all options appear to yield negative consequences). Despite being motivated to take action in disasters, terrorism, major investigations and complex political interventions, decision makers can become inert, looping between phases of situation assessment, option generation and option evaluation. This 'looping' is functionally redundant when it persists until they have lost the opportunity to take action. We define this as 'decision inertia': the result of a process of (redundant) deliberation over possible options and in the absence of any further useful information. In the context of critical incidents (political, security, military, law enforcement) we have discovered that rather than disengaging and avoiding difficult choices, decision makes are acutely aware of the negative consequences that might arise if they failed to decide (i.e., the incident would escalate). The sensitisation to possible future outcomes leads to intense deliberation over possible choices and their consequences and, ultimately, can result in a failure to take any action in time (or at all). We (i) discuss decision inertia as a novel psychological process of redundant deliberation during crises; (ii) define the concept and discuss the emerging studies in support of our tentative hypotheses regarding how the cognitively active process of deliberation can result in complete behavioural inactivity; and (iii) suggest recommendations and interventions for combatting inertia.
\end{abstract}

Keywords: Decision inertia; decision avoidance; redundant deliberation; anticipated consequences; uncertainty 


\section{Decision Inertia in Critical Incidents}

Although the world has faced numerous political, social and psychological challenges across centuries (e.g., first and second world wars), the challenges faced by Europe (and indeed the globe) in the $21^{\text {st }}$ century continue to grow. From the displacement of millions of refugees from war torn countries who have sought solace throughout Europe, to the instability caused by Brexit and the increase in right-wing extremism and isolationist ideologies, to the ever-increasing reality of terrorism as a constant threat; Europe is in a state of dynamic and uncertain change. Regardless of political or ideological viewpoints, this creates a challenge for policy makers and scientists alike, who must react and anticipate these changes whilst implementing actions to try and mitigate instability to a dynamic series of fluctuations across Europe and its relationships more widely. This paper will outline the importance of psychological research to help strategic decision makers implement choices despite instability, uncertainty and risk. This could include emergency responders reacting to a terrorist attack, political parties responding to the migrant crisis, or nation states deliberating over the Brexit deal. All these choices are characterised by uncertainty, conflicting information and opinions, and a limited opportunity to claw back consequences once actions have been set in place (irreversible decisions). Importantly, choices are typified by a tendency for significant delays or failures to take action due to prolonged, albeit redundant, deliberation; a process we term 'decision inertia'.

This paper makes a novel contribution to psychological theory by extending the research on the psychology of doing nothing (specifically doing nothing even in the face of significant external stimuli). Whereas a plethora of research has explored and tested the relationship between stimulus and response, relatively little research has studied the relationship between stimulus and non-response. As explored in the philosophical 'Buridan's ass' paradox, wherein a donkey who is equally thirsty and hungry dies when placed between 
hay and water since it cannot make a distinguishable choice, we are interested in what happens when someone needs to behave, but is unable to act. 'Decision inertia', a term originally coined by Alison et al. (2015), was used to describe the process of redundant deliberation over a choice for no positive gain ${ }^{1}$. Alison et al.'s (2015) paper focused principally on describing the authors' experiential observations of working with police, security and military with regards to decision derailments during critical incidents, presenting an example from a large scale live simulated exercise involving a plane crash. However, the paper provided little detail on defining, unpacking or exploring the conditions under which decision inertia occurred, or the psychological mechanisms that underpinned it. This paper provides a descriptive account of the psychological process of decision inertia and, with reference to the limited literature that has explored non-decision-making, outlines five hypotheses to test it empirically.

Decision inertia is a stimulus-non-response activity that, we argue, is poorly understood, under researched, and presents a methodological challenge. With regards to methods this is largely due to the fact that the majority of current methodological approaches are directed at measuring the presence of a given behaviour rather than the possible processes underpinning non-behaviour. Unlike decision avoidance, which describes inaction as a result of suspended disengagement with decision processing, decision inertia reflects behavioural inaction despite cognitive processing, and has been observed in the context of critical incidents (e.g., Power \& Alison, 2017). Decision inertia is characterised by redundant deliberation; the constant rumination over possible choices in the absence of further useful information. It is a cognitively active process that involves the decision maker (unhelpfully) modelling prospective future states that do not assist him / her in taking action (e.g. what

\footnotetext{
${ }^{1}$ Note: This is distinct from the definition of 'decision inertia' as a sub-optimal tendency to repeat previous choices independently of the outcome (see Alos-Ferrer, Hugelschafer \& Li, 2016)
} 
happens if things go wrong? What happens if I change my mind?). Take Buridan's ass: is she more likely to defer her choice by disengaging with the problem, or is she more likely to be engaged in intense deliberation about how to resolve her paradox?

\section{The context of decision inertia: critical incidents}

A decision is defined as a commitment to a course of action that is taken in order to achieve a desired goal (Yates, 2003). Making a decision requires that we operate on the environment, commit to an option and initiate behaviours directed at teleological goals. Merely thinking about a problem does not reflect a choice. Equally, thinking and choosing, but not acting, is insufficient. The hallmark of a 'good' decision is to wait until we have all available information to derive accurate inferences (Plous, 1993). Effective decision-making includes the ability to anticipate and prospectively model future states and consequences of action, as it motivates individuals to identify the steps required to reach a desired goal (Karniol \& Ross, 1996). Individuals who score highly on measures for "consideration of future consequences' and 'episodic future thinking' (i.e., they tend to think about future states) are less likely to procrastinate (Rebetez, et al., 2016), which suggests future thinking stimulates action. Yet, many important decisions are underpinned by ambiguous, incomplete or contradictory information, meaning that our capacity to make rational choices is bounded by the environment and cognition (Simon, 1956). In such instances, mental forecasting and deliberation about what we might do could be counterproductive: when should mental forecasting stop? Sometimes it is important to hold back to maximise outcomes - other times it may be prudent to take a least worst first approach. What dictates the appropriateness of these decision maxims is the decision context. 
Decision inertia as a concept emerged from the authors' real-world observations of decision-making and decades of ethnographic experience of research in critical incident settings; where decision-making was degraded not by making the wrong choice, but by delaying or failing to make any decision at all. It appears typical in contexts whereby: (i) choices are multi-attribute; involve (ii) one-time, irreversible consequences; (iii) in dynamic environments; where (iv) anticipated negative consequences are not only linked to action but also to inaction. The Boxing Day Tsunami (2004), the Haiti Earthquake (2010) and the ongoing refugee crisis in Europe are all incredibly diverse and emotionally salient emergencies that have one thing in common: the failure of authorities to take timely action (Grunewald, Binder \& Georges, 2010; National Audit Office, 2006; UNICEF, 2008). The emergency response to the devastating Haiti earthquake was criticised for being slow due to weak humanitarian leadership (Grunewald, et al., 2010) and poor prioritisation of relevant information (Patrick, 2011); uncertainty concerning roles, responsibilities and leadership were blamed for causing delays in the response to widespread flooding in the UK (Pitt, 2008). Consider also the decision faced by President Obama and the United States Government with the eruption and escalation of violence in Syria:

"Do nothing, and a humanitarian disaster envelops the region. Intervene militarily, and risk opening Pandora's box and wading into another quagmire like Iraq. Send aid to the rebels, and watch it end up in the hands of extremists. Continue with diplomacy, and run head first into a Russian veto. None of these approaches offered much hope of success”.

Clinton (2014, p.461)

Critical incidents are contexts in which individuals and teams make judgements whilst operating under rapidly changing and uncertain conditions (Militello, Sushreba, Branlat, 
Bean \& Finomore, 2015). They are high-stakes, severe consequence, highly ambiguous and unpredictable events (Alison \& Crego, 2007), characterised by missing and conflicting information (Bharosa, Lee \& Janssen, 2010) and exacerbated by time pressure (Chen, Sharman, Rao \& Upadhyaya, 2008) and damage to organisations (Alison and Crego, 2007). They place huge demands on the physical, psychological and interpersonal skills of the decision maker (Orasanu \& Lierberman, 2011), contributing to cognitive overload and stress (Paton \& Flin, 1999). A qualitative analysis of interviews with Emergency Service commanders highlighted how decision makers were not only driven by a desire to avoid causing poor outcomes through action, but were equally concerned about the negative consequences that might arise should they do nothing, tied to their role being in 'command' of the emergency (Power \& Alison, 2017): option A might be bad, option B might be worse, but the option of doing nothing at all might actually be worst of all. Decision inertia is characteristic of critical incidents as negative consequences do not only arise from poor choices, but can also arise if one fails to take any action at all (i.e., situation worsens).

\section{How is decision inertia distinct from other theories of 'non-decision-making'?}

In an early attempt at exploring the concept of non-decision-making, Anderson (2003) wrote a seminal paper on the study of 'decision avoidance'. He described avoidance as " $a$ pattern of behaviour in which individuals seek to avoid the responsibility of making a decision by delaying or choosing options they perceive to be nondecisions" (p.139, Anderson, 2003). He identified choice deferral ("I'll put this off until later"), status quo bias (“I'll just copy what everyone else does"), omission bias ("I choose to do nothing") and inaction inertia ("I have missed a previous better opportunity, so I'll wait and see if a better one arises") as four decision avoidance effects. Crucially, decision avoidance reflected disengagement with the decision process. 
Decision inertia extends Anderson's (2003) model by identifying a fifth type of nondecision-making characterised by a desire to commit to a choice; thereby not disengaging with the decision process, but engaging in effortful cognitive deliberation even when no further useful information is forthcoming. This extends Anderson's (2003) proposed antecedents to decision avoidance, where he argued anticipated regret/blame and selection difficulty lead to avoidance via, for example, choice deferral. We argue that when decisions are made in time critical contexts wherein the opportunity to implement a choice can be lost (e.g., patient dies whilst deliberating between options) that there is a fifth component to the psychology of doing nothing: continued cognitive deliberation until the opportunity to decide has passed. As with Buridan's ass, the decision maker is neither avoiding nor deferring the decision, but is constantly 'leaping' from one set of options to the other, to the point where the 'reward' for all the effort and deliberation between hay or water is death.

Related to inertia is work from the motivational literature - specifically with regards to the actual sequence of processes within a decision. For example, Gollwitzer's (1999) work (e.g., Aschziger \& Gollwitzer, 2007; Heckhausen \& Gollwitzer, 1987) on the model of action (or Rubicon model) identified four action phases underpinning decision-making: predecisional (deliberation between goals); postdecisional (implementation of goals via behaviour); actional (behavioural action); and postdecisional (review of goals and behaviour). He argued that the distinction between pre- and postdecisional phases is based upon the type of mindset used by the individual making a choice. Specifically, predecisional phases are led by deliberative mindsets (i.e., what to do?) whereas postdecisional phases are led by implemental mindsets (i.e., how to do it?). A critical point in transitioning from pre- to postdecisional mindsets is by forming a goal intention to direct behaviour. It is possible that decision inertia occurs when individuals are unable to identify a clear goal intention, thus inhibiting transition from deliberative to implementational mindsets. 
Similarly, Kalis, Mojzisch, Schweizer and Kaiser (2008) have described why people failed to act despite their intention to behave. They identified how intentions can be derailed during: (i) option generation (due to loss of goal directedness); (ii) option selection (due to impulsivity, compulsivity and ambivalence); and (iii) action initiation (due to motor difficulties and hyperactivity). Our notion of 'decision inertia' builds upon this model to identify how behavioural intentions can be derailed through redundant deliberation, which interferes with the entire decision-making process (Figure 1). Decision makers fail to progress to action as they oscillate between situation assessment, option generation and option evaluation, all whilst trying to trade off the potentially adverse negative prospective modelling of future states that arise from both taking action and not taking action ("what will this look like if I do A?' / 'what will this look like if I don't do A?').

Decision inertia is thus a cognitively demanding, but ultimately self-defeating, process of redundant deliberation over future states in the absence of any new or useful information. It is not decision avoidance, which reflects a choice to disengage with decision processing (Anderson, 2003). Decision inertia emerges from continuing in perpetuity about the choice, rather than choosing to ignore it. It incurs significant cognitive load. Decision inertia is not an adaptive process related to 'sensemaking'. Thinking and cognitive effort alone are insufficient for action and impact. Decision makers must consider whether it critical to act now or in the near future. If time is available, then they can search for more information and think more; if time is limited, they must be vigilant to the diminishing returns for further thinking. Indeed, previous research has shown a hallmark of expertise is the ability to accurately assess timelines (i.e. when to act) (Hoffman Ward, Feltovich, Di Bello, Fiore and Andrews, 2013) and experts have been found to rapidly detect and correct errors during problem solving (Patel, et al., 2011). Finally, decision inertia is not implementation failure (i.e., failure to execute action, despite cognitive commitment to an 
option). Implementation failure has been explored in organisational settings; wherein poor team structure, a lack of organisational cohesion and ineffective team management have all been associated to action failure (Decker, Durand, Mayfield, McCormack, Skinner \& Perdue, 2012; Taleai \& Mansourian, 2008). Decision inertia precedes the point of implementation failure as a choice is yet to be made.

\section{Hypothetical factors that might contribute to decision inertia}

We provide a descriptive model of decision inertia (Figure 1). It outlines how intentions can sometimes fail to produce action due to a process of redundant and continued deliberation during situation assessment, option generation and option evaluation. It illustrates how uncertainty and the anticipation of potential negative consequences underpin redundant deliberation. Crucially, it incorporates the context of the choice, by asking whether the decision maker can choose to do nothing; if so, they can avoid choice, if not, they return to redundant deliberation. Five hypothesised contributory factors to inertia are outlined below. Although this list is not exhaustive, it provides an initial basis upon which to develop further research on decision inertia. We suggest that, despite the methodological challenges for measuring inertia - the absence of behaviour - that empirical studies could be designed to test: (i) the time spent deliberating over choice; and (ii) physiological measures to detect arousal (and not disengagement) during this process. By designing studies wherein there is no clear or objective right or wrong answer (e.g., pick the red or blue pill), inertia can be measured by seeing how long for and how aroused participants remain despite there being no reward for cognitive processing; specifically, via manipulation of variables outlined in our five hypotheses.

\section{Hypothesis 1: Decision inertia will increase when information about the decision}

problem is ambiguous. Decision inertia is more likely to occur when information about the 
decision problem is ambiguous (Ellsberg, 1961) leading to uncertainty. This may occur when there is not enough information, or when there is too much information as decision makers struggle to process relevant pieces of information (Bharosa et al., 2010; Power \& Alison, 2017). Take the decision triggered by Brexit on free movement of people: policy makers might have multiple and conflicting information about how their choice will influence migration figures across Europe, whilst very little information on how their choice will affect societal and cultural harmony. Furthermore, an 'obsession with full information' has been identified as an 'avoidable pathology' during high-stakes events such as emergencies (Boin \& t'Hart, 2010). When available information about potential options is complex, deliberation might increase as individuals struggle to disentangle options, especially when they are unsure of acceptable choice thresholds (Chen, Ma \& Pethtel, 2011; White \& Hoffrage, 2009). In contexts where decision avoidance is possible, individuals can opt to disengage with cognitive processing; yet when a decision is required, we argue that decision makers will redundantly deliberate in an attempt to reduce uncertainty, even when there is little chance of additional information helping their choice.

Ambiguity derails choice because it limits the decision maker's confidence in their ability to accurately make sense of the situation and prospectively model future states (Klein, Snowdon, \& Pin, 2007; Lipshitz \& Strauss, 1997; van den Heuvel, Alison \& Crego, 2012). An informed understanding of the decision environment enables the decision maker to anticipate consequences and distinguish between courses of action. However, when a situation is ambiguous, it can increase the perceived risk associated with the consequences for choices and potential regret, decreasing action likelihood (Anderson, 2003). Importantly, when making high-stakes choices wherein negative consequences can also arise for doing nothing (i.e., as the situation will get worse), then redundant deliberation might occur in attempts to trade off risk between action and inaction. In managerial settings, it was found 
that task ambiguity and risk led to implementation failure (Brooks, 2011; Decker et al., 2012); yet in contexts where inaction is equally aversive, decision makers are unlikely to disengage. Ambiguity is hypothesised to contribute to decision inertia by increasing redundant deliberation to try and resolve uncertainty and avoid negative consequences.

\section{Hypothesis 2: Decision inertia will increase when there is social or team}

uncertainty. Decision inertia will increase when operating in social or team-based settings where there is ambiguity about the team structure. Alison, Power, van den Heuvel and Waring (2015) explored police decision-making in a simulated hostage negotiation incident and found that feelings of uncertainty were not only associated with task ambiguity, but arose due to social ambiguity (e.g., poor understanding of roles within the team network). Police, Fire and Ambulance commanders must make decisions as a coordinated team by relying on information from one another; yet, the mere presence of others creates uncertainty as individuals make their own choices whilst monitoring those of others (van Harreveld, van der Pligt \& Nordgren, 2008). Individuals operating in team settings are five times more likely to defer their choice than when the same decision problem is given to individuals (White, et al., 2011). In contexts where choice deferral is not an option, it is anticipated that the presence of others will increase decision inertia. Indeed, decision inertia could explain the ongoing prolonged and redundant deliberation over the Brexit deal (despite no new information arising), which is exacerbated by the sheer number of European partners involved whose roles and responsibilities for decision-making lack clarity.

Issues of trust in team settings might also influence decision inertia. A culture of mistrust can increase redundant deliberation as individuals consider whether they can trust the information they have received from others rather than focussing on the task (Alison et al., 2015; Bond \& Nolan, 2011; Mamhidir, Kihlgren \& Sorlie, 2007). When working with disliked others, individuals anticipate more regret for making a wrong choice (Kumar, 2004), 
which may increase redundant deliberation in order to avoid regret. People try to avoid deciding when they anticipate potential negative feedback from others about their choices (Zeelenberg \& van Dijk, 1997). This could involve the salience of anticipated loss (Crotty \& Thompson, 2009), the anticipation of blame (Eyre, Alison, Crego, \& Mclean, 2008, Zeelenberg, van Dijk, Manstead \& van der Pligt, 2000), and the perceived inability to personally justify choice (Beeler \& Hunton, 1997; Brooks, 2011; Dhar, 1997). Thus, social ambiguity related to trust in the team network can contribute to decision inertia, as individuals redundantly deliberate over the trustworthiness of information rather than focussing on the decision task to try and avoid potential negative outcomes.

\section{Hypothesis 3: Decision inertia will increase when managing conflicting or}

contradictory goals. Decision inertia will arise when a task involves multiple contradictory and conflicting goals. For example, European states deliberating over the refugee crisis might feel conflicted between humanitarian goals to support displaced refugees against nationalist goals to protect the resources of their nation state. Goals are important for decision-making as they help to orient and motivate behaviour in pursuit of desired outcomes (Locke \& Latham, 1990). Different types of goals have been found to have different effects on behaviour. For example, 'avoid goals' (to avoid negative outcomes) are associated with increased deliberation on a choice as individuals try and avoid potential negative consequences for acting (Corr \& McNaughton, 2012); whereas approach goals (i.e., when one seeks to achieve positive outcomes) are associated with increased action implementations (Elliot, 2006). However, approach goals can be maladaptive when it is difficult to trade off equally attractive outcomes (Boyd, Robinson, \& Fetterman, 2011) and decision-makers feel unable to justify their choice (Dhar, 1997; Novemsky, Dhar, Schwarz \& Simonson, 2007). This is linked to 'maximising' (i.e., select the best possible outcome) wherein decision-makers use 'alternative-based' cognitive processing strategies to judge if any options are good enough, 
increasing their tendency to focus on subjectively meaningful attributes and raising their threshold of acceptance (Parker \& Schrift, 2011).

Although goals can be useful to guide behaviours, vague goals can derail behaviour by contributing to uncertainty (Locke \& Latham, 1999). Goals can be vague when multiple goals compete with each other, making it difficult to identify which goal to prioritise at that point in time. In an exploratory study on decision inertia in Emergency Response Commanders, it emerged that decision inertia seemed to occur when commanders struggled to trade-off approach goals to 'save life' with avoid goals to 'prevent harm' (Power \& Alison, 2017). The authors suggested that commanders redundantly deliberated because they feared violating both these goals; wanting to take action due to their organisational responsibility, but also wanting to avoid action due to the (unintentional) risk of negative outcomes as a result of action. More recent research (Shortland \& Alison, 2017) has observed these effects as a function of competing 'sacred' values. In military contexts, armed forces were more likely to engage in redundant deliberation when forced to choose between two sacred military values such as 'protect my own men' vs. 'complete the mission'. It is argued that decision inertia can be stimulated by calculating a set of sacred values and forcing individuals to choose between them. The more sacred the competing values, the more prone to decision inertia.

\section{Hypothesis 4: Decision inertia will increase in those who are less experienced in}

the choice context. Domain-specific experience facilitates decision-making since individuals are able to rapidly process the choice environment and generate solutions to difficult problems (Klein, Calderwood \& Clinton-Cirocco, 1986). The more experienced an individual is, the less likely they are to perceive risk or experience dread associated with choice (Bond \& Nolan, 2011). Experience enables people to process their choice efficiently, even when the task is objectively complex (Bornstein, Emler \& Chapman, 1999; Braverman \& Blumenthal- 
Barby, 2012); for example, an experienced police officer responding to a terrorist incident will be better able to manage their stress levels than a member of the public as they have more knowledge about the choice context. Experts have relevant task-specific knowledge (Stanovich \& West, 2008), which allows them to use 'gut instinct' and intuition (Klein, et al., 1986); relying upon accurate implicit and explicit 'recognition primed' mental models, developed through repeated exposure in the choice environment (Klein, 2008; Roswarski \& Murray, 2006). It was found in the fire service that experienced commanders were more likely to progress to action implementation following plan formulation, whereas novices were equally as likely to return to situation assessment again (Cohen-Hatton, Butler, \& Honey, 2015). Experience is predicted to reduce decision inertia as experts use intuitive and learned responses and are better able to adapt to the time demands of the situation and judge when deliberation must stop and a decision must be made.

Interestingly it has been found that the effect of deliberation as a processing style on decision quality is moderated by experience. One study found that both novices and experts made no worse or better (respectively) choices when asked to deliberate on their choice; however, the performance of 'intermediates' (those who had experience, but only modest knowledge about the specific task context) degraded following deliberation (Dijkstra, van der Pligt \& van Kleef, 2013). This suggests that those with experience, but limited experience applying this knowledge to the given task domain, perform worse following deliberation. This might explain why inertia has been observed in emergency contexts. The decisionmaker is experienced in their role, but they may be less experienced in applying this knowledge to the specific intricacies of an unpredictable emergency incident, which could induce perpetual deliberation. It might be useful to train decision-makers to sensitize them to an awareness of when deliberative stopping rules should be applied, to improve the usefulness of deliberation during time pressured emergencies. Shortland, Alison and Moran 
(in press) have shown that military personnel seem to be relatively less susceptible to decision inertia than other groups and have suggested this may be a function of having more experience of bad outcomes and greater tolerance of least worst choices.

\section{Hypothesis 5: Individual differences in 'decisiveness' traits will predict the}

likelihood of decision inertia. A final hypothesis is that decision inertia will be more prevalent in those with indecisive personality traits. Personality research has identified how certain individuals possess traits that can influence the way that they process decisions (Brooks, 2011). When asked to choose between options, trait 'indecisive' individuals tend to use maladaptive cognitive processing styles that systematically compare all alternatives whilst utilising extremely high thresholds of acceptance (Patalano \& Wengrovitz, 2007). They fail to make a choice as they try and find the perfect option (i.e., are any options good enough?). This decision-making strategy would be undesirable during complex decision tasks, such as Brexit, wherein objective 'right' outcomes are highlight unlikely to emerge. Alternatively, 'decisive' individuals use adaptive attribute-based search patterns to select a compromise option from those that are available (i.e., which option is the best?). 'Indecisive' individuals might be predisposed to redundant deliberation and inertia. Likewise, high scores on 'state-orientation' (i.e., a tendency to focus on negative emotions and ruminate on past) as opposed to 'action-orientation' (i.e., a tendency to focus on the present task) is associated with greater rumination on emotions as opposed to the decision task (van Putten, Zeelenberg \& van Dijk, 2009), and those high on 'need to compare' (i.e., tendency to engage in social comparisons with others) often struggle to make decisions as they redundantly deliberate over social comparisons rather than the decision task (Gibbons \& Buunk, 1999; van Dijk \& Zeelenberg, 2005).

Other traits associated with delayed decision-making include: 'desire for control' (i.e., desire to maintain control over decision outcomes) (Thomas, Buboltz, Teague \& Seeman, 
2011); 'outcome sensitivity' (i.e. motivation to avoid post-decisional feedback) (Dholakia, Gopinath \& Bagozzi, 2005); 'neuroticism' (Wong, Yik \& Kwong, 2006); and trait 'avoidance' (versus approach) motivations (Corr, DeYoung \& McNaughton, 2013; HarmonJones Harmon-Jones \& Price, 2013). Those personalities that are associated with indecision, can be collectively described as reflecting poor cognitive flexibility; as they are unable to adapt to the demands of the problem environment and instead engage with continued deliberation in line with their (inappropriate) values (Roskes Elliot, Nijstad \& De Dreu, 2013). Thus, indecisive individuals are expected to show greater decision inertia as they have a chronic disposition for redundant deliberation. Further research is needed to unpack how individual differences in cognitive processing styles and personality interact with the tendency for inertia.

\section{Possible solutions to reduce decision inertia}

Whilst it is important that researchers study the processes that underpin decision inertia, it is equally important that researchers also seek to develop solutions to reduce its effects. This is particularly important in terms of having impact on the European and world stage, by helping critical decision makers better cope with uncertainty in high-stakes environments. One possible solution that we would like to highlight is decision-making training; specifically, to assist decision makers with structuring the way in which they process information in complex contexts. The ability to make sense of and evaluate information to select that which is useful (and equally reject that which is not) comes from experience; however, experience takes time to build.

One solution might be via the development and use of scenario-based learning and immersive simulated environments to support deliberate practise and feedback (Alison et al., 2013; Colvin Clark, 2014). There are also approaches that may help decision makers with 
especially complex and multi-source information sources that some have suggested provide a useful cross check on the perception of what matters; such as Analysis of Competing Hypotheses, which encourages decision-makers to weigh alternative explanations of conclusions (Heuer, 1999). Training interventions might also include multi-team exposure, so that individuals are better able to process information and make decisions due to knowledge of the team structure, and training could further be developed to help decision-makers better manage their goals and expectations of when and where an inertia 'trap' is likely. Thus, we argue that research is first needed to better understand the conditions under which decision inertia might arise, but we caveat that such research must be crucially supported by insight on how to reduce its effects in these applied environments. In practitioner domains, this can be via the development of training or new policies and procedures to help critical decisionmakers navigate their choices.

\section{Conclusion}

Psychologists have developed considerable expertise in helping us to understand the links between environment, behaviour and human cognition by experimenting on and observing the relationship between stimulus and response. But there has been limited attention paid to understanding the relationship between stimulus and non-response. This is important in a $21^{\text {st }}$ century Europe and across the globe, where decisive action regarding migration, political unrest and terrorism is needed more than ever. This paper has taken a first step in clearly defining, identifying and highlighting the concept of decision inertia as a process that might explain why strategic decision-making can derail. Decision inertia is not an adaptive form of sensemaking ("I am still discovering the facts about my available options"); it is not decision avoidance ("I choose not to decide for the time being"); and it is not implementation failure ("I have made my choice but the translation of my choice into action has failed"). Decision inertia is a process of failing to take action due to constant and 
redundant deliberation about the problem ("I am still thinking about whether I will commit to, refuse or avoid my choice"). It results in behavioural freezing caused by intense cognitive deliberation, despite there being little or no chance of further information alleviating efforts. There are both conceptual and methodological challenges for researching the absence of behaviour; yet the benefits for tackling these challenges are huge, spanning from theoretical knowledge to real-world impact that might help us to manage a changing Europe.

Fundamentally, this paper has hoped to stimulate psychological enquiry so that we can more fully understand the psychological processes that don't only explain why people make decisions, but importantly why, at times, they do not. 
RUNNING HEADER: DECISION INERTIA

\section{References}

Achtziger, A., \& Gollwitzer, P.M. (2007). Rubicon model of action phases. Encyclopedia of social psychology, 2, 769-770.

Alison, L., \& Crego, J. (2007). Policing critical incidents: Leadership and critical incident management. Devon, England: Willan Publishing.

Alison, L., Power, N., van den Heuvel, C., \& Waring, S. (2015). A taxonomy of endogenous and exogenous uncertainty in high-risk, high-impact contexts. Journal of Applied Psychology. Online first. http://dx.doi.org/10.1037/a0038591

Alison, L., Power, N., van den Heuvel, C., Humann, M., Palasinksi, M., \& Crego, J. (2015). Decision inertia: deciding between least worst outcomes in emergency responses to disasters. Journal of Occupational and Organisational Psychology. Online first. DOI: $10.1111 /$ joop.12108\#

Alison, L., van den Heuvel, C., Waring, S., Power, N., Long, A., \& O’Hara, T. (2013). Immersive simulated learning environments for researching critical incidents: A knowledge synthesis of the literature and experiences of studying high-risk strategic decision-making. Journal of Cognitive Engineering and Decision Making, 7(3), 255272.

Alos-Ferrer, C., Hugelschafer, S., \& Li, J. (2016). Inertia and Decision Making. Frontiers in Psychology, 7, 169. DOI: 10.3389/fpsyg.2016.00169.

Anderson, C.J. (2003). The Psychology of doing nothing: forms of decision avoidance result from reason and emotion. Psychological Bulletin, 129, 139-167. 
Beeler, J.D., \& Hunton, J.E. (1997). The influence of compensation method and disclosure level on information search strategy and escalation of commitment. Journal of Behavioural Decision Making, 10, 77-91.

Bharosa, N., Lee, J., \& Janssen, M. (2010). Challenges and obstacles in sharing and coordinating information during multi-agency disaster response: Propositions from field exercises. Information Systems Frontier, 12, 49-65.

Boin, A., \& 't Hart, P. (2010). Organising for effective emergency management: Lessons from research. Australian Journal of Public Administration, 69(4), 357-371.

Bond, L., \& Nolan, T. (2011). Making sense of perceptions of risk of diseases and vaccinations: a qualitative study combining models of health beliefs, decision-making and risk perception. Public Health, 11, 1-14.

Bornstein, B.H., Emler, C.A., \& Chapman, G.B. (1999). Rationality in medical treatment decisions: is there a sunk-cost effect? Social Science \& Medicine, 49, 215-222.

Boyd, R.L., Robinson, M.D., \& Fetterman, A.K. (2011). Miller (1944) revisited: Movement times in relation to approach and avoidance conflicts. Journal of Experimental Social Psychology, 47(6), 1192-1197.

Braverman, J.A., \& Blumenthal-Barby, J.S. (2012). Social Science \& Medicine, 75, 186-192.

Brooks, M.E. (2011). Management indecision. Management Decision, 49(5), 683-693.

Chen, M., Ma, X., \& Pethtel, O. (2011). Age differences in trade-off decisions: older adults prefer choice deferral. Psychology and Ageing, 26 (2), 269-273.

Chen, R., Sharman, R., Rao, H.R., \& Upadhyaya, S.J. (2008). Coordination in emergency response management: Developing a framework to analze coordination patterns 
occurring in the emergency response life cycle. Communications of the ACM, 51(5), $66-73$.

Clinton, H. (2014). Hard Choices. London, UK: Simon \& Schuster UK Ltd.

Cohen-Hatton, S.R., Butler, P.C., \& Honey, R.C. (2015). An investigation of operational decision-making in situ: Incident command in the UK Fire and Rescue service. Human Factors, 57, 793-804.

Colvin Clark, R. (2014). Evidence-based training methods. ATD Press: Alexandria, VA.

Corr, P.J., \& McNaughton, N. (2012). Neuroscience and approach/avoidance personality traits: A two stage (valuation-motivation) approach. Neuroscience and Biobehavioural Reviews, 36, 2339-2354.

Corr, P.J., DeYoung, C.G., \& McNaughton, N. (2013). Motivation and personality: A Neuropsychological perspective. Social and Personality Psychology Compass, 7/3, $158-175$.

Crotty, S.K., \& Thompson, L. (2009). When your heart isn't smart: how different types of regret change decisions and profits. International Journal of Conflict Management, 20(4), 315-339.

Dallaire, R. (2004). Shake Hands with the Devil: The Failure of Humanity in Rwanda. Arrow Books: Vauxhall Bridge, London.

Decker, P., Durand, R., Mayfield, C.O., McCormack, C., Skinner, D., \& Perdue, G. (2012). Predicting implementation failure in organization change. Journal of Organizational Culture, Communications and Conflict, 16(2), 39-59 
Dhar, R. (1997). Context and task effects on choice deferral. Marketing Letters, 8(1), 119130.

Dholakia, U.M., Gopinath, M., \& Bagozzi, R.P. (2005). The role of desires in sequential impulsive choices. Organisational Behaviour and Human Decision Processes, 98, 179-194.

Dijkstra, K.A., van der Pligt, J., \& van Kleef, G.A. (2013). Deliberation versus intuition: Decomposing the role of expertise in judgment and decision-making. Journal of Behavioural Decision Making, 26, 285-294.

Elliot, A.J. (2006). The hierarchical model of approach-avoidance motivation. Motivations and Emotion, 30, 111-116.

Ellsberg, D. (1961). Risk, ambiguity, and the savage axioms. The Quarterly Journal of Economics, 75(4), 643-669.

Eyre, M., Alison, L., Crego, J., \& Mclean C. (2008). Decision inertia: the impact of organisations on critical incident decision-making. In L.J. Alison \& J. Crego, Policing Critical Incidents: Leadership and Critical Incident Management. Devon, UK: Willan Publishing.

Gibbons, F.X., \& Buunk, B.P. (1999). Indifferences in social comparison: Development and validation of a measure of social comparison orientation. Journal of Personality and Social Psychology, 76, 129-142.

Gollwitzer, P.M. (1999). Implementation intentions: strong effects of simple plans. American Psychologist, 54(7), 493-503. 
Grünewald, F., Binder, A., \& Georges, Y. (2010). Inter-agency real time evaluation in Haiti: Three months after the earthquake. URD and GPPI.

Harmon-Jones, E., Harmon-Jones, C., \& Price, T.F. (2013). What is approach motivation? Emotion Review, 5(3), 291-295.

Heckhausen, H., \& Gollwitzer, P.M. (1987). Thought contents and cognitive functioning in motivational versus volitional states of mind. Motivation and Emotion, 11(2), 101120.

Kalis, A., Mojzisch, A., Schweizer, T.S., \& Kaiser, S. (2008). Weakness of will, akrasia, and the neuropsychiatry of decision-making: An interdisciplinary perspective. Cognitive, Affective and Behavioral Neuroscience, 8(4), 402-417.

Karniol, R., \& Ross, M. (1996). The motivational impact of temporal focus: Thinking about the future and the past. Annual Review of Psychology, 47, 593-596.

Klein, G. (1998). Sources of power: How people make decisions. Cambridge, MA: MIT Press.

Klein, G.A., Calderwood, R., \& Clinton-Cirocco, A. (1986). Rapid decision-making on the fireground: In Proceedings of the Human Factors and Ergonomics Society $30^{\text {th }}$ Annual Meeting (Vol. 1, pp. 576-580). Norwood, NJ: Ablex.

Klein, G., Snowden, D., and Pin, C.L. (2007). Anticipatory Thinking. Proceedings of the Eighth International NDM Conference, Pacific Grove, CA, June 2007.

Kumar, P. (2004). The effects of social comparison on inaction inertia. Organizational Behavior and Human Decision Processes, 95, 175-185. 
Lipshitz, R., \& Strauss, O. (1997). Coping with Uncertainty: A Naturalistic Decision-Making Analysis. Organizational Behavior and Human Decision Processes, 69(2), 149-163. Locke, E.A., \& Latham, G.P. (1990). A Theory of Goal Setting and Task Performance. Englewood Cliffs, NJ: Prentice-Hall.

Mamhidir, A.G., Kihlgren, M., \& Sorlie, V. (2007). Ethical challenges related to elder care. High-level decision-makers' experiences. BMC Medical Ethics, 8 (3), 1-10.

Militello, L.G., Sushreba, C.E., Branlat, M., Bean, R., \& Finomore, V. (2015). Designing for military pararescue: Naturalistic decision-making perspective, methods, and frameworks. Journal of Occupational and Organizational Psychology, 88(2), 251272.

Novemsky, N., Dhar, R., Schwarz, N., \& Simonson, I. (2007). Preference fluency in choice. Journal of Marketing Research, 347-356.

National Audit Office / Foreign \& Commonwealth Office. (2005). Joint findings on lessons to be learned from the handling of the response to the Indian Ocean tsunami. Retrieved from http://www.nao.org.uk/report/consular-services-to-british-nationals/

Orasanu, J., \& Lieberman, P. (2011). NDM issues in extreme environments (pp.3-22). In K.L. Mosier \& U.M Fischer (eds). Informed By Knowledge. Hove: Psychology Press.

Patrick, J. (2011). Evaluation Insights Haiti Earthquake Response Emerging Evaluation Lessons. Evaluation Insights, 1, 1-13.

Parker, J.R., \& Schrift, R.Y. (2011). Rejectable choice sets: how seemingly irrelevant nochoice options affect consumer decision processes. Journal of Marketing Research, 840-845. 
Patel, V.L., Cohen, T., Muraka, T., Olsen, J., Kagita, S., Myeni, S., Buchman, T., \& Ghaemmaghami, V. (2011). Recovering at the edge of error: Debunking the myth of the infallible expert. Journal of Biomedical Informatics, 44(3), 413-412.

Paton, D., \& Flin, R. (1999). Disaster stress: an emergency management perspective. Disaster Prevention and Management: An International Journal, 8(4), 261-267.

Power, N., \& Alison, L. (2017). Redundant deliberation about negative consequences: decision inertia in emergency responders. Psychology, Public Policy \& Law. 23(2), 243-258.

Rebetez, M.M.L., Carsics, C., Rochat, L., D’Argembeu, A., \& van den Linden, M. (2016). Procrastination, consideration of future consequences and episodic future thinking. Consciousness and Cognition, 42, 286-292.

Roskes, M., Elliot, A.J., Nijstad, B.A., \& De Dreu, C.K.W. (2013). Time pressure undermines performance under avoidance than approach motivation. Personality and Social Psychology Bulletin, 39(6), 803-813.

Roswarski, T.E., \& Murray, M.D. (2006). Supervision of students may protect academic physicians from cognitive bias: A studt of decision-making and multiple treatment alternatives in medicine. Medical Decision Making, 26, 154-161.

Shortland, N, \& Alison, L. (In Press). Conflict: How Soldiers Make Impossible Decisions. Oxford University Press.

Simon, H. A. (1956). Rational choice and the structure of the environment. Psychological Review, 63, 129-138. 
Stanovich, K.E., \& West, R.F. (2008). On the relative independent of thinking biases and cognitive ability. Personality Processes and Individual Differences, 94(4), 672-695.

Taleai, M., \& Mansourian, A. (2008). Using Delphi-AHP Method to Survey Major Factors causing urban plan implementation failure. Journal of Applied Sciences, 8(15), 27462751.

Thomas, A., Buboltz, W.C., Teague, S., Seemann, E.A. (2011). The Multidimensionality of the Desirability of Control Scale (Burger \& Cooper, 1979). Individual Differences Research, 9 (3), 173-182.

UNICEF (2008). 2004 Indian Ocean Earthquake and Tsunamic: Lessons learned. UNICEF. Accessed on $11^{\text {th }}$ June 2015, available from http://www.unicef.org/har08/index_tsunami.html

van den Heuvel, C., Alison, L., \& Crego, J. (2012). How uncertainty and accountability can derail strategic 'save life' decisions in counter-terrorism simulations: a descriptive model of choice deferral and omission bias. Journal of Behavioral Decision Making, $25,165-187$.

van Dijk, E., \& Zeelenberg, M. (2005). On the psychology of 'if only': regret and the comparison between factual and counterfactual outcomes. Organisational behaviour and human decision processes, 97, 152-160.

van Harreveld, F., van der Pligt, J., \& Nordgren, L. (2008). The relativity of bad decisions: social comparison as a means to alleviate regret. British Journal of Social Psychology, 47, 105-117. 
van Putten, M., Zeelenberg, M., \& van Dijk, E. (2009). Dealing with missed opportunities: Action vs state orientation moderates inaction inertia. Journal of Experimental Social Psychology, 45, 808-815.

White, C. M., \& Hoffrage, U. (2009). Testing the tyranny of too much choice against the allure of more choice. Psychology and Marketing, 26, 280-298.

White, C.M., Hafenbradl, S., Hoffrage, U., Reisein, N., \& Woike, J.K. (2011). Are groups more likely to defer choice than their members? Judgement and Decision Making, 6(3), 239-251.

Wong, K.F.E., Yik, M., \& Kwong, J.Y.Y. (2006). Understanding the emotional apects of escalation of commitment: the role of negative affect. Journal of Applied Psychology, 91(2), 282-297.

Yates, J.F. (2003). Decision Management. San Francisco: Jossey-Bass.

Zeelenberg, M., \& van Dijk, E. (1997). A reverse sunk cost effect in risky decision-making: sometimes we have too much invested to gamble. Journal of Economic Psychology, 18, 677-691.

Zeelenberg, M., van Dijk, W.W., Manstead, A.S.R., \& van der Pligt, J. (2000). On bad decisions and disconfirmed expectancies: the psychology of regret and disappointment. Cognition and Emotion, 14(4), 521-541. 


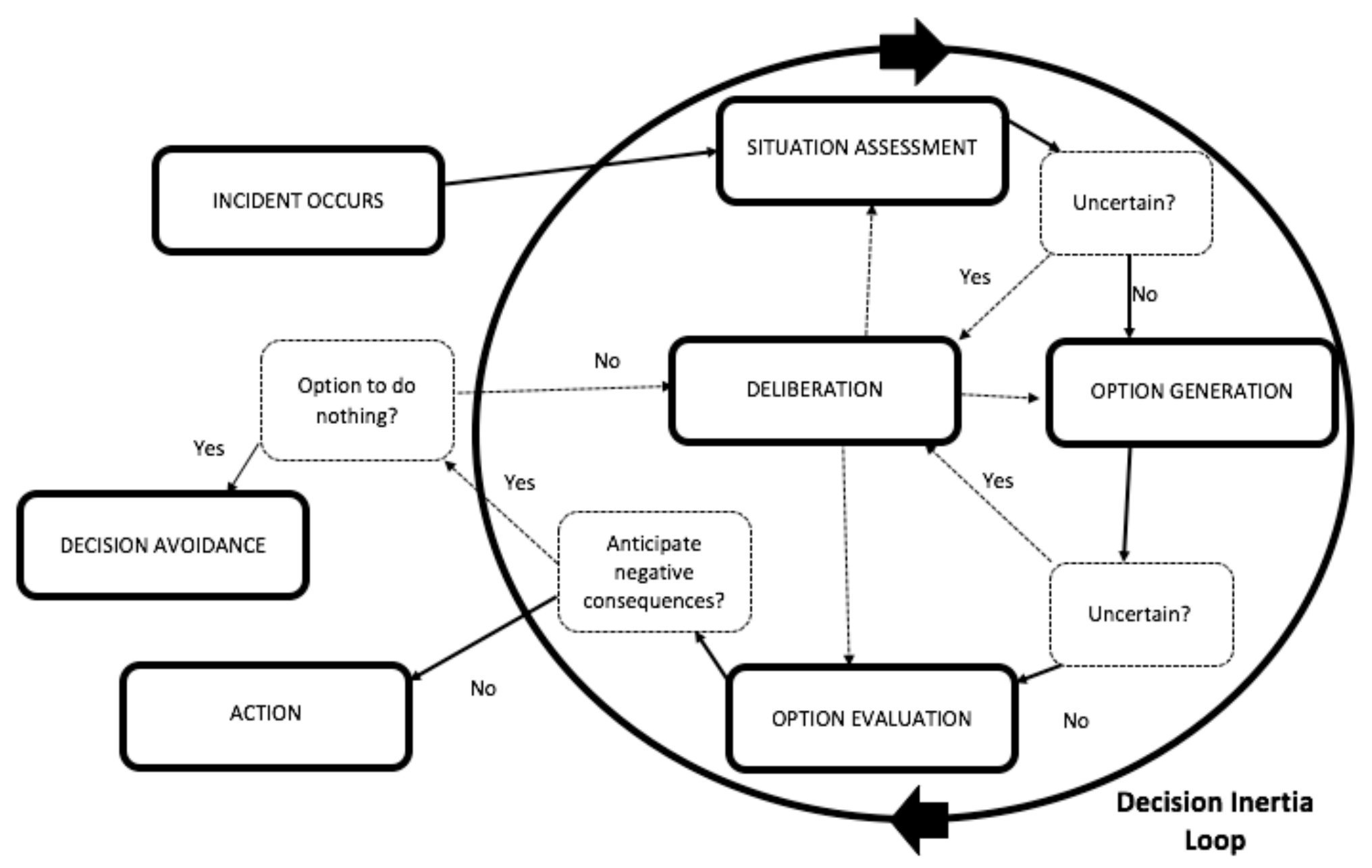

Figure 1: Descriptive model of decision inertia 